\title{
FPD Supported Cu-Sil Like Denture - A Simplified Approach to Preserve the Teeth and Bone
}

\author{
K. Savitha', Manoharan PS $^{2}$, Rajkumar E ${ }^{3}$, Balaji. $\mathbf{J}^{4}$ \\ ${ }^{1}$ III Year Post Graduate, Department of Prosthodontics, Indira Gandhi Institute of Dental Sciences, Puducherry. \\ ${ }^{2}$ Professor and Head, Department of Prosthodontics, Indira Gandhi Institute of Dental Sciences, Puducherry. \\ ${ }^{3}$ Reader, Department of Prosthodontics, Indira Gandhi Institute of Dental Sciences, Puducherry. \\ ${ }^{4}$ Reader, Department of Prosthodontics, Sri Venkateshwaraa Dental College, Ariyalur.
}

Corresponding Author: K. Savitha

\begin{abstract}
$\mathrm{Cu}-\mathrm{Sil}$ denture is a simplified approach which helps in preserving the few remaining natural teeth .It is a new type of transitional denture which clasps the neck of the tooth providing space for the remaining teeth to emerge into the oral cavity through the denture. Preserving the remaining teeth not only preserves the alveolar ridge but also maintains proprioception providing psychological benefit for the patient. $\mathrm{Cu}$-Sil denture is one such simpler clinical approach which offers many advantages. This case report represents a simple chair-side clinical approach to fabricate $\mathrm{Cu}-\mathrm{Sil}$ denture by preserving the few natural teeth.
\end{abstract}

Keywords: $\mathrm{Cu}-\mathrm{Sil}$ denture, transitional denture, proprioception

\section{INTRODUCTION}

De van stated that "the perpetual preservation of that what remains is more important than meticulous replacement of what is missing". ${ }^{[1]}$ The prime concern of present day dentistry is to preserve the teeth and ridge as much as possible which may lead to success of the prosthesis. ${ }^{[2]}$ Several studies have shown that removing all the natural teeth for the fabrication of complete denture and wearing it for a longer time may eventually lead to bone loss, reduced stability and retention of the prosthesis thereby decreased masticatory efficiency and undermined esthetic appearance causing psychological trauma among the patients. ${ }^{[3]}$

Va Crum and Rooney in one of their studies have proved that the amount of bone resorption is relatively less when few teeth are present compared to completely edentulous patients. ${ }^{[3]}$ Treatment options for patients with very few remaining natural teeth includes immediate dentures, overdenture or transitional dentures. ${ }^{[4]}$ Over- dentures cannot serve solution for all cases as it has many requirements which includes proper positioning of the remaining teeth, requires more number of appointments, oral hygiene maintenance with frequent follow ups. Patients defer for extracting all the teeth and go in for removable prosthesis ${ }^{[5,6]}$ So in cases where immediate dentures or over-dentures are not been opted by the patient, transitional denture plays a role in treating those patients. Cusil denture is one such transitional denture which is found to be a simplified approach as well as an affordable treatment option for patients with few remaining natural teeth

\section{CASE REPORT}

A 65 year old male patient reported to the department of Prosthodontics, Indira Gandhi institute of dental sciences with the complaint of difficulty in chewing and speaking and wanted replacement of the missing upper and lower teeth. On clinical examination, patient presented with Upper 
completely edentulous arch and lower partially edentulous arch with missing in relation to $31,32,33,34,35,36,37,38,41$, $42,47,48$. In the lower arch, Only four teeth were remaining: $43,44,45,46$ of which 43 were periodontally compromised with grade 2 mobility and requires definite extraction (Figure1). He was also a previous denture wearer for the past 15 years (Figure 2). Oral hygiene was fair and extra oral examination showed no significant findings. Patient was not willing for extraction of the remaining teeth, but he was willing to do Root canal treatment in relation to 34,35 , 36. And so Intentional root canal treatment was done in relation to $34,35,36$ followed by restoration with porcelain fused metal crown and cusil denture fabrication in lower arch and complete denture in upper arch.

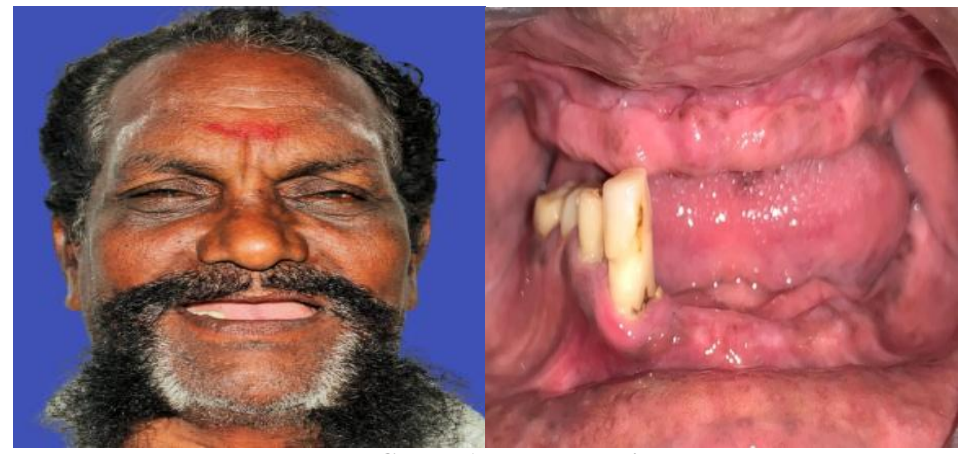

FIGURE 1: Intraoral view

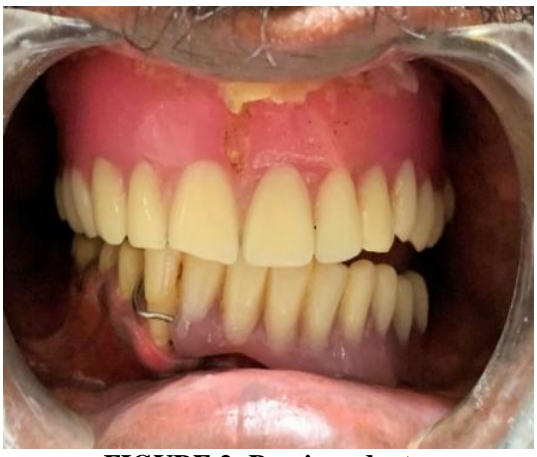

FIGURE 2: Previous dentures

\section{Procedure:}
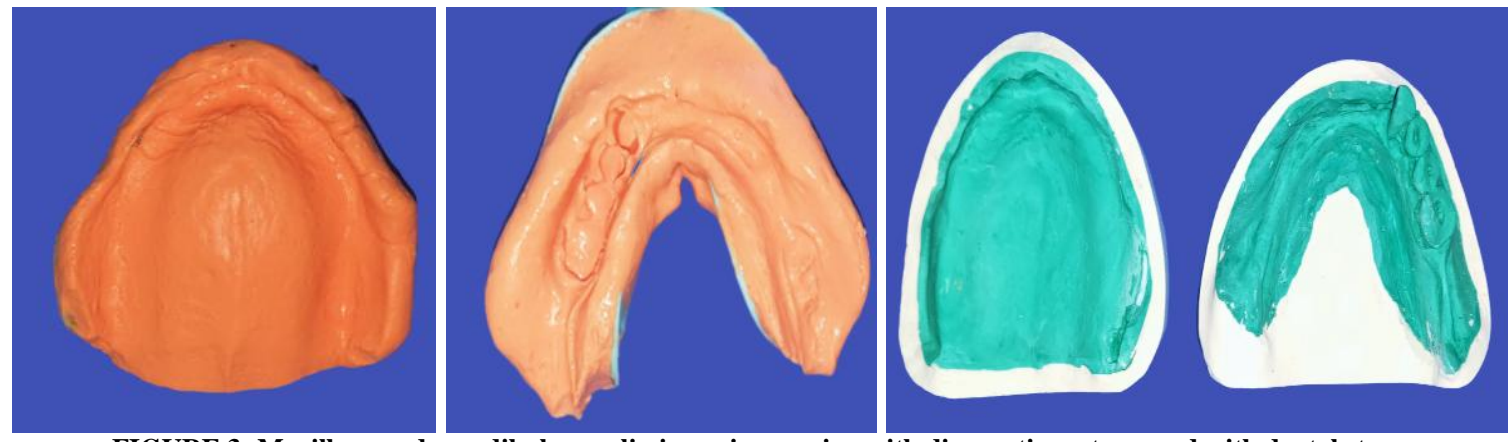

FIGURE 3: Maxillary and mandibular preliminary impression with diagnostic cast poured with dental stone

Maxillary and Mandibular impressions were made with irreversible hydrocolloid impression material (Dentsply) and study cast was poured with dental stone. (Figure 3)

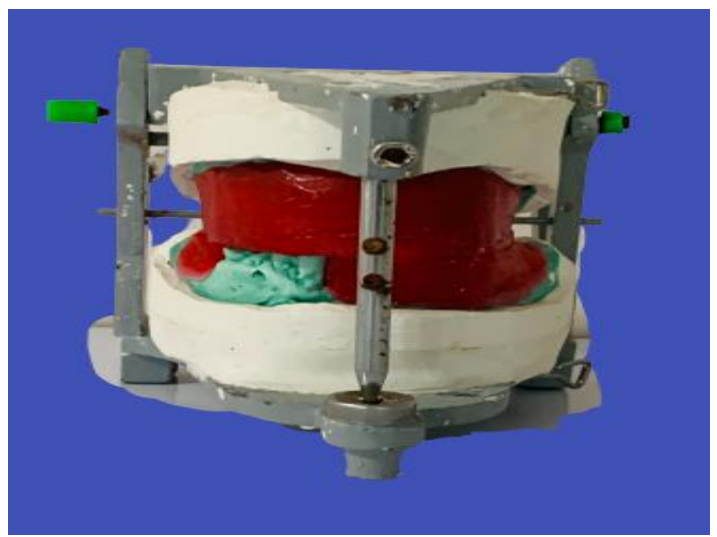

FIGURE 4: Tentative jaw relation
Tentative jaw relation was done and articulated in the mean value articulator to evaluate the interarch space.(Figure 4)

Interarch space was adequate and was planned for intentional rct in relation to $34,35,36$ followed by porcelain fused metal ceramic restoration.

Bridge preparation was done in relation to $34,35,36$ followed by cementation of the porcelain fused metallic bridge with Type 1 glass ionomer cement.

Special tray was fabricated for upper arch using autopolymerizing resin and border molding is done with green stick compound followed by light body silicone impression. Lower arch impression was 
made with putty and light body impression material. (Figure 5)
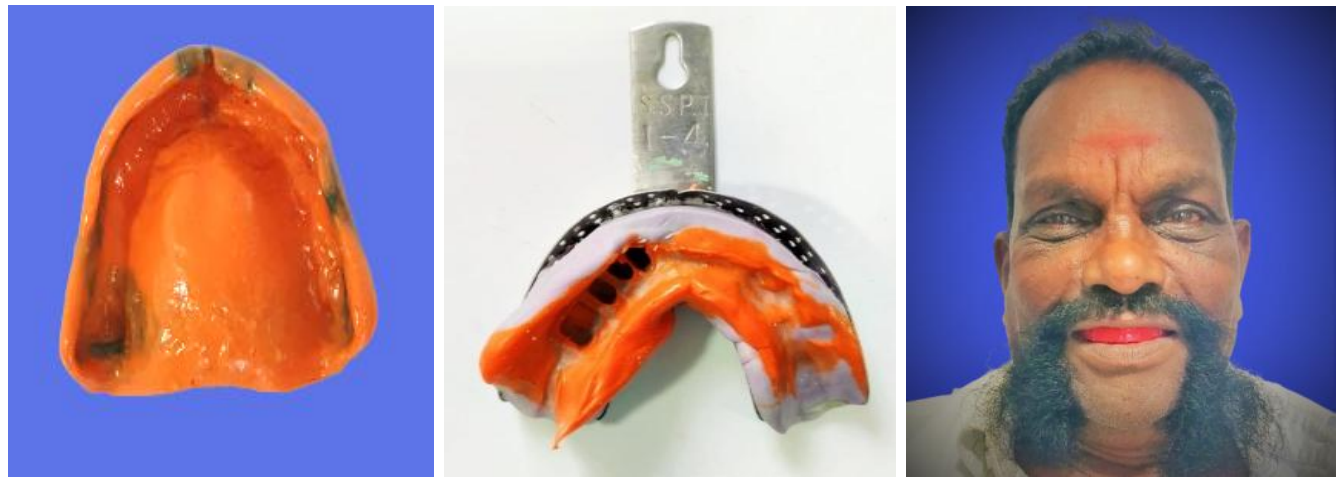

Figure 5 : Secondary impression

Figure 6: Bite registration



Figure 7:Try in of upper and lower teeth setting
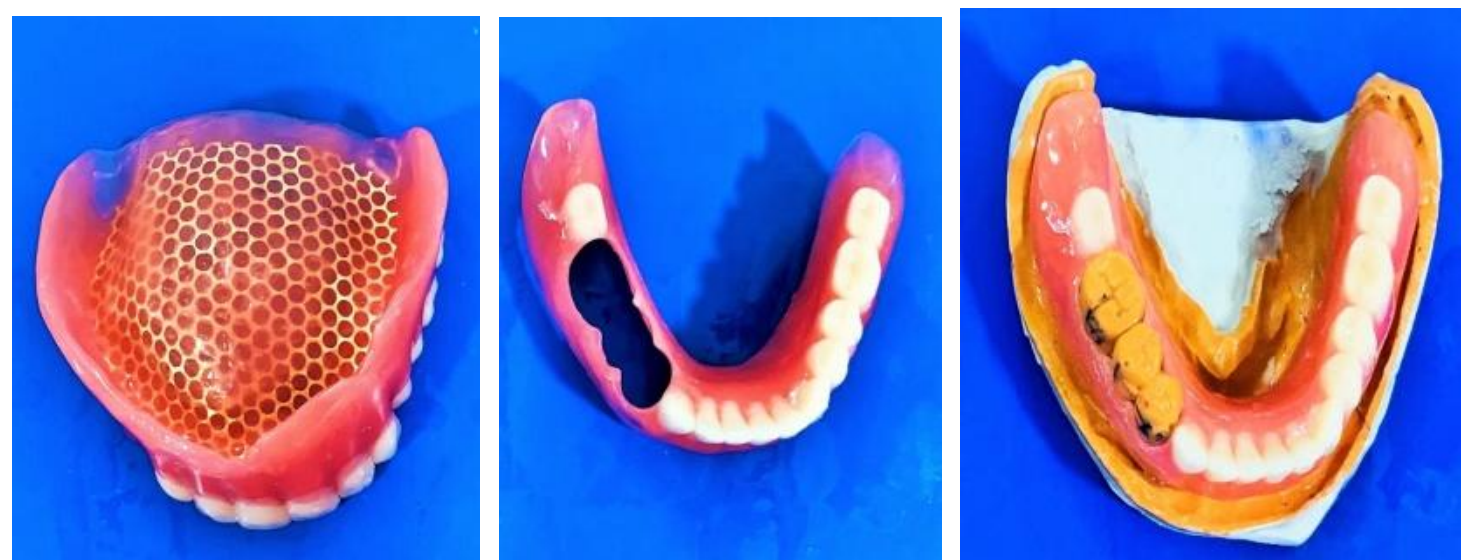

FIGURE 8: Upper Complete denture and lower cusil like denture.

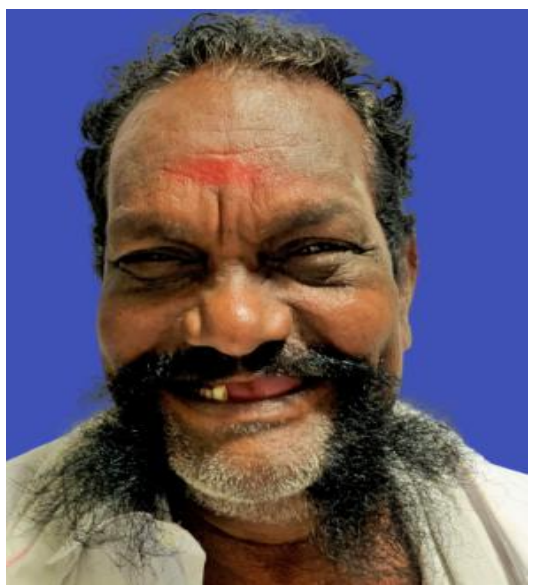

PREOPERATIVE VIEW

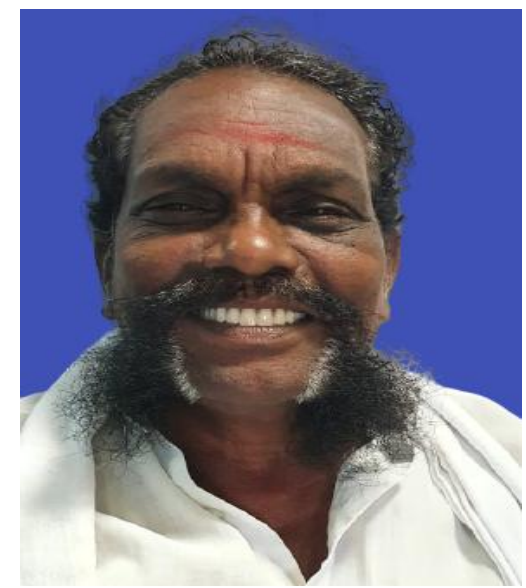

POST OPERATIVE VIEW

Figure 9: Pre-operative \& Post-operative image 
Secondary cast is made, Temporary Denture bases were fabricated with autopolymerising resins, occlusal rims were made and bite registration was done. (Figure 6)

Set up was mounted on the articulator and teeth arrangement was completed and try in was done for upper and lower arch. (Figure 7)

Denture processing was done using conventional technique with incorporation of mesh in upper denture. (Figure 8)

Upper complete denture and lower fixed partial supported cusil denture delivery was done.

\section{DISCUSSION}

Patients with very few remaining natural teeth can be treated with either of the treatment options:immediate dentures or overdentures or transitional dentures. Overdentures may not favour all the cases as it needs to be endodontically treated,requires more visits and hygiene maintenance whereas getting all the teeth extracted and going on for immediate dentures may psychologically affect the patient. ${ }^{[8,9,10]}$ Cusil denture is one such clinical approach which is designed to preserve the few remaining natural teeth and bone giving psychological benefit for the patient. ${ }^{[11]}$ Fixed partial supported cusil like dentures increases the retention and stability of the prosthesis thereby improving the attitude of the patient as the natural teeth is preserved. Masticatory efficiency is also improved when compared to conventional complete denture patients as proprioception is preserved in such patients. This treatment modality does not require any special armamentarium or materials whereas if the tooth is lost in future denture can be modified to occupy its place. Cusil dentures are associated with some disadvantages like it requires frequent corrections and also since the entire margin of the gingiva is covered by the denture, it may lead to plaque accumulation. ${ }^{[12]}$

\section{Indications:}

- Periodontally comprimised teeth

- Single/Isolated teeth in the arch

- To eliminate extractions of the remaining few natural teeth

- Need for transitional denture

- For psychological benefit of the patient

\section{Contraindications:}

- Presence of so many teeth

- Non-cooperative patients

- In cases with severe undercuts.

- Bruxism

- Patients with high smile line.

\section{CONCLUSION}

Cusil like denture is not a very common procedure but still it is an acceptable and one of the best treatment option for patients with few remaining natural teeth as it preserves the natural teeth and bone thereby improving the masticatory efficiency, speech providing psychological benefit for the patient.

\section{Acknowledgement: None}

\section{Conflict of Interest: None}

\section{Source of Funding: None}

\section{REFERENCES}

1. George A. Zarb, Charles L. Bolender, Judson C. Hickey, Gunnar E. Carlsson. Boucher's Prosthodontic treatment for edentulous patients, 10th ed. Mosby.71- 99.

2. Jain JK, Prabhu CA, Al Zahrane M, Al Esawy MS, Ajagannanavar SL, Pal KS. Cusil dentures-a novel approach to conserve few remaining teeth. Journal of international oral health $2015 ; 7(8): 138$.

3. Crum RJ, Rooney Jr GE. Alveolar bone loss in overdentures: a 5-year study. Journal of prosthetic dentistry. 1978 ;40(6):610-3.

4. Zarb-Bolender: Prosthodontic treatment for edentulous patients, 12th ed. Mosby.623,160-176,190-208

5. Sheldon Winkler: Essentials of complete denture prosthodontics, 2nd ed.Ishiyaku Euro America Inc.U.S.A. 22- 34,384-402 . 
6. Khandelwal M, Punia V. Saving one is better than none- Technique for cu-sil denture -A Case report. Annals \& Essences of Dentistry. 2011;3(1).

7. Jain AR. Cu-sil denture for patients with few remaining teeth-A case report. Journal of Advanced Pharmacy Education \& Research. 2017;7(3).

8. Guyer SE. Selectively retained vital roots for partial support of overdentures: A patient report. The Journal of prosthetic dentistry. 1975;33(3):258-63.

9. Schwartz IS, Morrow RM. Overdentures. Principles and procedures. Dental clinics of North America. 1996;40(1):169-94.

10. Van Waas MA, Jonkman RE, Kalk W, Van't Hof MA, Plooij J, Van Os JH. Differences two years after tooth extraction in mandibular bone reduction in patients treated with immediate overdentures or with immediate complete dentures. Journal of dental research.1993;72(6):1001-4.

11. Gagandeep K, Sangeetha G, Deepika S. Cusil denture: A novel conservative approach-A case report. Unique J Med Dent Sci.2013;1(02):56-8.

12. Walter JD. A study of partial denture designs produced by an alumni group of dentists in health service practice. The European journal of prosthodontics and restorative dentistry. 1995;3(3):135-9.

How to cite this article: K. Savitha, Manoharan PS, Rajkumar E et.al. FPD supported cu-sil like denture - a simplified approach to preserve the teeth and bone. Int J Health Sci Res. 2021; 11(6): 130-134. DOI: https://doi.org/10.52403/ ijhsr.20210618 